\title{
Contribuição da etnografia dos Jê Meridionais à Arqueologia
}

\author{
Juracilda Veiga *
}

VEIGA, J. Contribuição da etnografia dos Jê Meridionais à Arqueologia. R. Museu Arq. Etn, 27: 21-29, 2016.

Resumo: Os Kaingang e Xokleng são as etnias que constituem o ramo Jê Meridional. Apesar das suas transformações culturais ao longo do tempo, concepções profundas e nucleares de identidade cultural são persistentes, caso dos Kaingang que são extremamente arraigados a alguns de seus referentes culturais. Este texto trata de alguns aspectos da cosmologia e socialidade dos Kaingang e enfatiza a relação destes dois aspectos com a construção de habitações, espaços rituais e monumentos funerários. A autora procura ressaltar que aspectos da espacialidade dos Kaingang e Xokleng podem ser identificados pelas pesquisas arqueológicas.

Palavras-chave: Kaingang, Xokleng, Cosmologia e Socialidade, Espacialidade, Arqueologia.

$\bigcirc$ s povos hoje conhecidos como Kaingang e Xokleng (ou Laklãnõ) constituem as etnias remanescentes do ramo Jê Meridional. No processo milenar em que se constituíram e, depois, desapareceram algumas das etnias e línguas desse ramo Jê (como os Ingain, em território hoje argentino), com certeza houve muitas mudanças, influências por contato cultural e, inclusive, simplificações. Cremos, porém, que as concepções mais profundas e nucleares da identidade cultural terão permanecido, o que se respalda também no fato de que os Kaingang são extremamente arraigados a alguns referentes. Muitos exemplos históricos mostram que povos em diáspora costumam ser mais conservadores.

Os povos Jê são famosos pela recorrência de pares de metades (Maybury-Lewis 1979; Seeger et al. 1979). Para os Kaingang, o mundo é perfeitamente simétrico, formado de pares antitéticos e complementares. Esse princípio totalizador da sua análise do mundo é personificado nos

(*) Fundação Nacional do Índio (FUNAI).<juracilda@ gmail.com> heróis míticos Kamẽ e Kanhru', fundadores da sociedade Kaingang. Os Kaingang afirmam que o sol é Kamẽ e a lua Kaĩru (Nimuendajú [1913] 1993: 60), embora não assumam, nem seus mitos enunciem ${ }^{2}$, que as metades clânicas sejam sol e lua, como é comum a outros povos Jê.

"As metades Kamẽ e Kaĩru são idealmente exogâmicas e, em tudo, complementares. A relação de troca entre as metades é permanente. Casa-se na metade oposta, enterram-se os mortos da outra metade, e quando alguém passa por um periodo de liminaridade é acompanhado e servido por pessoas da metade contrária" (Veiga 2000: 84).

$\mathrm{O}$ mito de origem Kaingang refere uma grande inundação que destruiu a terra conhecida, na qual morreram afogados seus ancestrais Kamẽ e Kanhru, cujas almas foram morar no interior da Serra de Krinjijimbé, e de onde

1 Em outros trabalhos grafei como Kaĩru, mas aqui optei por Kanhru que é o uso ortográfico desta língua.

2 Nimuendajú aponta que "talvez sejam Kamẽ e Kaneru nada mais que personificações do sol e da lua" ([1913] 1993: 61). 
saíram, ressuscitados: Kamẽ saiu por um lado que não tinha água [OESTE], e Kanhru pelo lado onde havia água (nascentes) [LESTE]. Julgo correto relacionar "sem água" com o Oeste e "com água" com o Leste porque, ao relatar esse mito, Paulino Aracxó justificou que, por conta do "dique" (a Serra do Mar) construído por patos e saracuras ao final do "dilúvio", as águas que nascem no território Kaingang correm todas de Leste para o Oeste.

Historicamente os Kaingang habitavam as regiões altas, sendo as nascentes lugares importantes para a purificação dos viúvos e cura de doenças. Os Xokleng preferiam os campos, de onde foram expulsos pela colonização, abandonando suas plantações de milho, feijão e moranga, como registrou Henry ([1941] 1964: 3).

Os Kamẽ estão relacionados ao sol, à persistência, à permanência, à dureza e aos lugares baixos e a objetos longos. Os Kaĩru estão relacionados à lua, ao orvalho, à umidade, à mudança, à agilidade, a lugares altos e a objetos baixos e redondos. A unidade é a soma desses princípios (Veiga 2000: 85). Os Kaingang tanto no Xapecó (SC) quanto em Rio da Várzea, me disseram que os Kamẽ nasceram no baixo e os Kaĩru nasceram no alto. Conforme Nimuendajú, os sentidos geográficos de "alto" e "baixo" correspondem, respectivamente, a Leste e Oeste (esse último, onde o Sol desaparece ou se afunda).

Portanto, o Kamẽ está no baixo, o coloca no Oeste, como em contrapartida, Kanhru, alto, no Leste. Há também um elemento astronômico que apoia a relação de Kamẽ = Sol com Oeste, e de Kanhru = Lua com Leste: $\mathrm{o}$ único momento astronômico (mensal) em que Sol e Lua estão PLENOS no céu é no nascimento da Lua Cheia, quando o Sol está se pondo (Oeste) e a Lua nascendo (Leste).

Os Kaingang construíam aldeias fixas, onde ficavam suas roças e cemitério. $\mathrm{O}$ mito da agricultura está relacionado também aos enterramentos: foi do corpo de um velho Kamẽ (segundo ouvi de pessoas mais velhas, em Inhacorá, RS), chamado Nhara - segundo o registro de Telêmaco Borba (Borba 1908), que surgiram as principais (e tradicionais) plantas cultivadas pelos Kaingang. Nhara (na forma registrada por Borba, ou Gãr, na forma orto- gráfica atual) é o nome que se dá ao milho3. Horta Barbosa (Barbosa 1913) informa, para os Kaingang paulistas, que os principais rituais de Kiki, destinados aos espíritos dos mortos, aconteciam na época da colheita do milho. $\mathrm{O}$ mito da agricultura entre os Kaingang foi recolhido no Paraná, na região do Tibagi (PR), por Telêmaco Borba e um século depois pude registrar, no Ivaí (PR), o mesmo mito:

"Primeiro índio fez milho, milho pururuca. Outro morreu. Naquele tempo, ele estava junto com o sogro. Ele falou para o genro: vamos fazer roça. Naquele tempo, não tem foice, cortando vara, daí roçando a taquara. Então ele falou para ele: Quando queimar essa roça, daí mata eu. Daí põe o cipó no [meu] pescoço, dai pode levar todos para o pari... Dai vai lá no pari, comer peixe. Naquele tempo não tinha milho. Ele estava lá 4 mês, lá no pari, o genro dele. Ele colocou na sombra [o corpo do sogro], na beira da roça. Tirou samambaia do xaxim e colocou sobre o corpo. Daí deixou ele. Depois de 4 meses eu venho ver a roça. Quando ele chegou lá na casa dele, tinha aquele feijão cacho comprida; aquele é costela dele. Depois unha de mão, aquele feijão de vara. Depois aquele unha do pé, feijão grande. Depois milho pururuca; aquele está misturado preto com branco, aquele é tikanẽ, os olhos dele. É bem isso. Daí ele comeu junto com peixe, faz bolo. Daí ele [o sogro] chegou lá na casa dele, [genro]:

- Como está tua roça? - Está tudo bom. -

Então eu vou embora, não vou voltar mais. Daqui dois mil ano tem que voltar. Você não vai sofrer mais tem milho, tem feijão. Ele foi colher".

[Josué Pantu Gino - T.I. Ivaí 24/04/1999]

3 Corteletti et al (no prelo) informam a presença de mandioca, juntamente com milho, feijão e abóbora, entre outras coisas, em potes cerâmicos de uma estrutura culinária em uma casa subterrânea na região de Urubici, no planalto catarinense, a partir da análise de fitólitos e grãos de amido. Essas evidências indicam que os Je/Itararé tinham uma dieta diversificada em época pré-colonial, pois esse material está datado em torno de $1350 \mathrm{AD}$, ou seja, anterior em alguns séculos a todas as evidências etnohistóricas. Nos relatos etnográficos não encontramos nenhum registro do uso da mandioca entre os Jê Meridionais - D’Angelis e Veiga (inédito). 
A agricultura tem origem num rito sacrificial: um Kamẽ chamado Nhara ou Ngãrã (Gãr) dá a sua vida em sacrifício. É transformado em milho, feijão e morangas, e com isso livra para sempre os Kaingang da fome. O período de abundância de peixes se alterna ao da colheita. Quando voltavam para a aldeia, depois de um período nos paris, era época de fazer festa das primícias e enterrar os mortos ou fazer uma cerimônia, que equivale a um segundo enterro, dos falecidos no último ano: o ritual para os mortos, ou Kikikoi [comer o kiki].

$\mathrm{O}$ fato de que as metades exogâmicas KAMẼ e KANHRU estão relacionadas aos pontos cardeais (Oeste e Leste, respectivamente) não transparece nas ações cotidianas, mas apenas na cerimônia do Kiki e nos enterra-

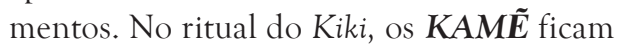
no lado Oeste da praça de dança e usam pintura facial com motivos compridos (rá téj), e os KANHRU ficam do lado Leste da praça de dança e usam pintura facial com motivos redondos (rá ror). Os espaços entre os dois grupos são marcados com uma divisória feita com folhas de xaxim ou samambaia que sempre são usados como separadores de situações liminares, uma espécie de isolante. Cada metade comporta duas seções: na metade KAMẼ as seções KAMẼ e Vãnh-jẽnky (Wonhétky); na metade KANHRU, as seções Kanhru e Votor. Os termos ror e téj são também traduzidos em português como «baixo» e «alto", respectivamente (Val Floriana 1920: 171; 184).

A importância dos conceitos ror e téj é fundamental para fins comparativos com pinturas rituais de outros Jê. As pinturas dos Xavante e Xerente são diferenciadas em redondas e compridas, como as dos Kaingang. Enquanto a dos Krahó, Suyá e Apinayé opõem listas horizontais a listas verticais que, se pensadas como baixo e alto, seriam equivalentes aos mesmos termos ror e téi (Veiga 2006: 80-83).

Em Julho de 1990, em visita a Vicente Fernandes, líder cultural que organizou a retomada do ritual do Kiki, ele afirmou: "O Kamẽ é enterrado para o poente, e o Kanhru para o nascente. Os pés é sempre para a porta do cemitério". (Na aldeia Pinhalzinho, onde viveu Vicente e onde o pai dele está enterrado, a porta do cemitério está voltada para o poente). Ele disse também: "O Kamẽ é para o lado de baixo, rãpur-ja, e o Kanhru é para o lado de cima" (portanto rãmur-ja). Rã-pur - esconder do sol, Rã-mur - nascer do sol.

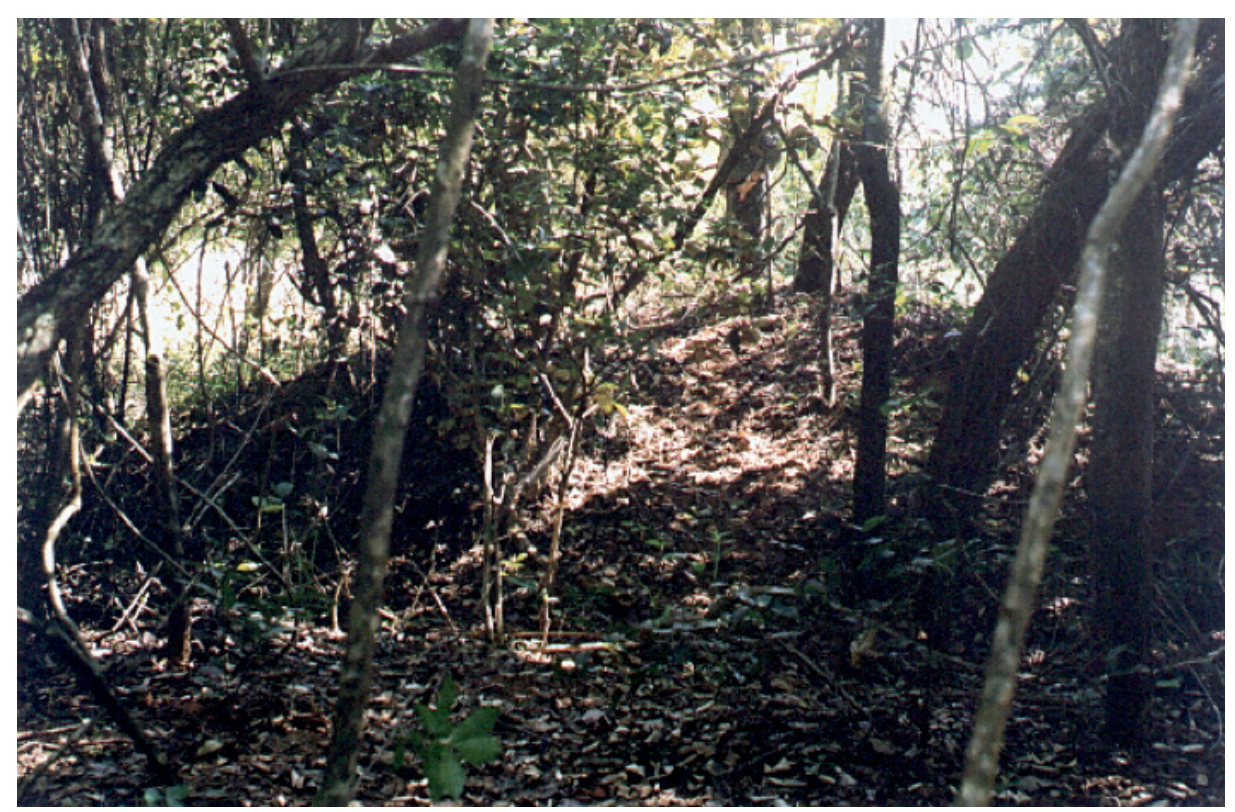

Fig. 1. Túmulo circular em Vanuíre, Arco-Íris, SP, 1998. 


\section{Posição no cemitério}
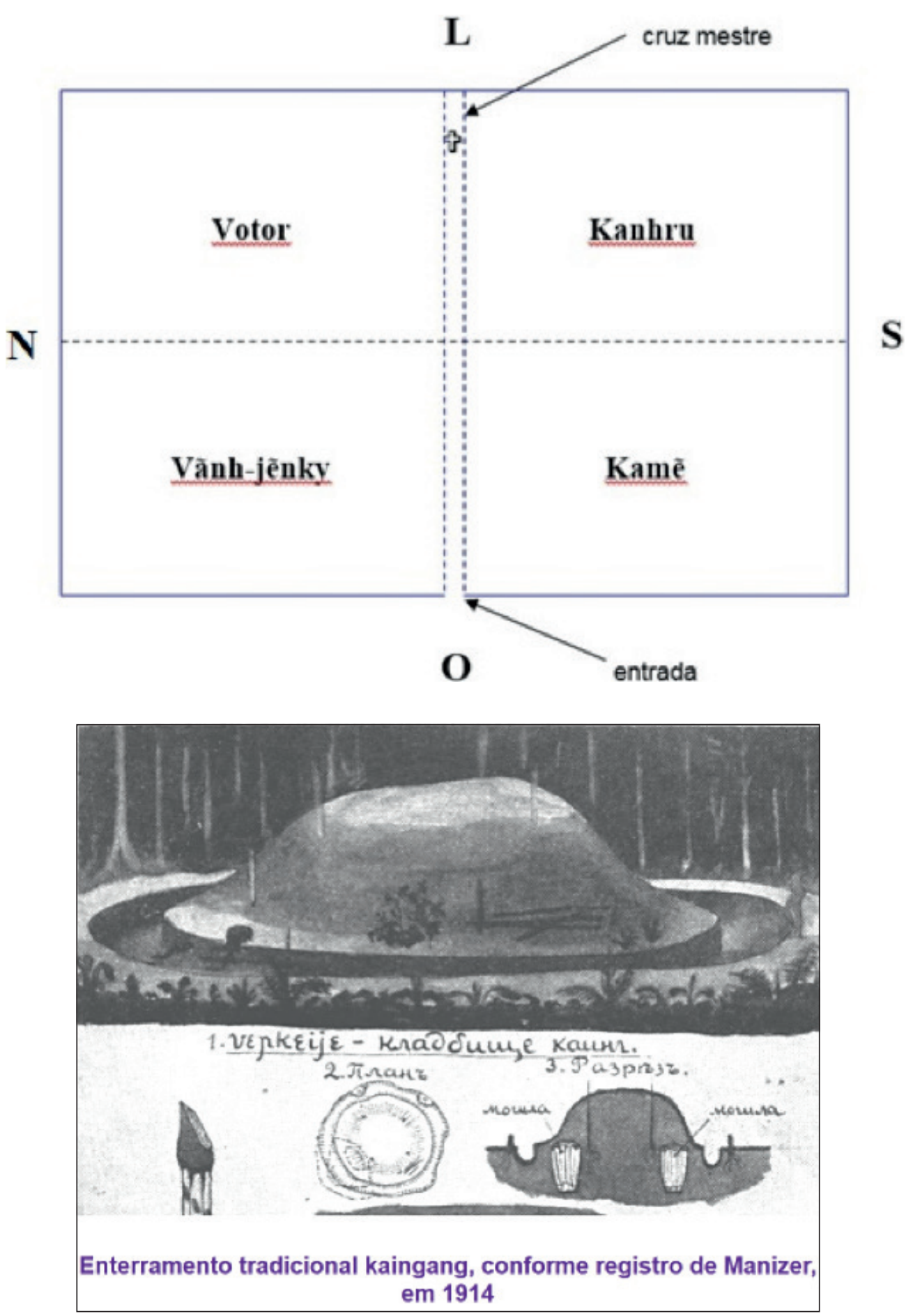

Fig. 2. Posição no cemitério e enterramento Kaingáng. 


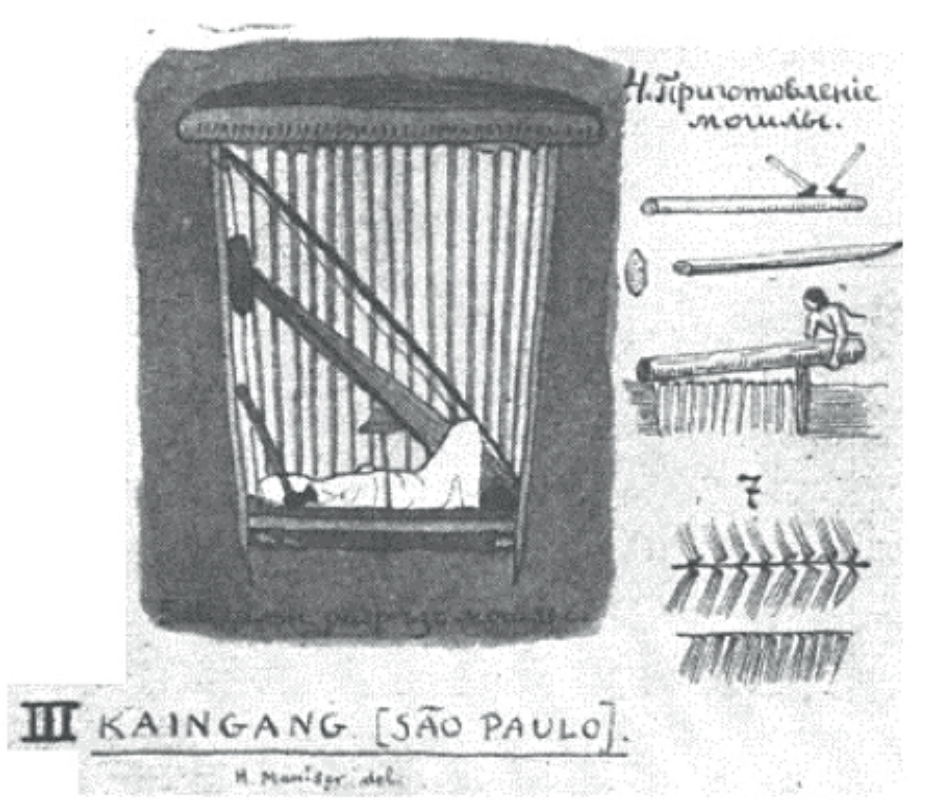

Fig. 3. Enterrramento Kaingang (Maniser 1930).

\begin{abstract}
A forma tradicional da sepultura Kaingang que a partir do século XX, em função do contato intenso com a sociedade brasileira, foi abandonada (fig. 1). Esses desenhos do cemitério e da posição do morto na sepultura foram registrados por Manizer em 1915, quando pode conviver com os últimos Kaingang a ser contatados, os do oeste Paulista (fig. 2). Graças a esse registro podemos relacionar as grandes estruturas arquitetônicas que envolvem movimentação de terra para construir habitações, espaços rituais e monumentos funerários, diretamente com os Kaingang e Xokleng (fig. 3).

Os Jê Meridionais, entre outras coisas, se diferenciavam, segundo os registros que até hoje conhecemos, entre os que cremavam seus mortos (os Xokleng) e os que faziam monumentos de terra sobre seus enterramentos. Telêmaco Borba relata, para o Paraná, lugares onde havia sinais de cremação. Nesses lugares onde se realizava o kiki era feita uma festa com cantos e danças dirigidos aos mortos recentes. Os Kaingang afirmam que "dançam sobre os mortos". Essa é a origem de monumentos de terra, os danceiros encontrados pelos arqueólogos.
\end{abstract}

\section{Sobre o Hábito da cremação}

Tenho a suspeita que talvez a cremação fosse destinada a uma categoria de pessoas, e se isso for correto, poderia haver cremação tanto de Xokleng como de Kaingang. Entre os Kaingang, os construtores dos monumentos funerários são uma categoria de pessoas que são chamadas de péin. Elas são invulneráveis aos espíritos dos mortos. Os péin são chamados de servidores, e eu os associo aos patos e saracuras que, na narração do "dilúvio" no mito de origem são os responsáveis por ir derramando terra sobre as águas, formando uma espécie de aterro através do qual saem, do cume da Serra, aqueles Kaingang e Kurutõ que haviam chegado até lá. Esse aterro teria formado a própria serra do mar, de modo que o cacique Arakxó, ao narrar o mito, informa que por isso os rios de suas terras correm do leste para o oeste e vão dar no grande Paraná.

Os Kaingang possuem um estoque de nomes próprios que podem ser dados ao se nominar as crianças. Esses nomes estão relacionados aos clãs ou seções e são recebidos 
por linhagem paterna: os filhos são da mesma qualidade de seu pai. Em cada metade existem também nomes que são próprios dos péin. Esses nomes são especialmente dados às crianças que ficam doentes e, portanto, vulneráveis e suscetíveis de serem levadas pelas almas dos seus parentes mortos, para a aldeia dos mortos. Nessa circunstância seu nome é trocado pelos rezadores e kujá (lê-se "kuiâ") por um nome péin. Isso lhe poupa a vida, mas é agregado ao nome anterior, ou simplesmente substitui o nome anterior, e é chamado de jiji korég, "nome ruim ou feio". Por toda a sua vida ele terá que cuidar dos mortos e fazer todos os trabalhos relacionados aos mortos, como fazer as comidas dos velórios (que antigamente aconteciam no cemitério), durante o tempo no qual alguns deles abriam as sepulturas. Alguns cronistas registram que um morto era imediatamente levado para o local da sepultura e se construía um pequeno rancho para abrigá-lo, ficando ele coberto com seu kuru ou com folhas de coqueiro ou samambaia. $\mathrm{O}$ velório era acompanhado exclusivamente pelas pessoas péin cujos nomes são considerados fortes. Os que possuíam jiji há, isto é, "nomes bons ou bonitos" (fracos) não podiam ir ao cemitério. Só o faziam por ocasião do kiki, ou segundo enterro, quando eram pintados com carvão, pinturas que os distinguiam dos espíritos dos mortos.

Um exemplo de nome péin é Ngatufi (sendo "fi" a marca de feminino), e a função dela é carregar terra em pequenos cestos. Outro nome péin é pehoter - "moranga morrer", que relaciona essa pessoa com o mundo dos mortos. Os Kaingang sempre dizem que quando passa um cheiro de moranga no ar é porque passou um espírito de morto, e que os mortos, por comerem muita moranga, têm esse cheiro característico.

Alguns Kaingang afirmam que os péin não podiam ser enterrados no cemitério junto com os demais porque eles comem os espíritos dos outros mortos. De algumas pessoas falecidas se diz que teriam sido enterradas num local à parte. No Inhacorá (RS), por exemplo, informam que a sepultura do cacique Fongue é separada, em um local em que ele está sozinho, porque ele era muito forte, não podia ser enterrado com os demais. Mas avento a possibilidade de que, no passado, os péin fossem cremados para não ameaçar os outros espíritos. Se eles podem comer os outros espíritos, os mortos têm medo deles e por isso, só eles podem lidar com os mortos e eles não compartilham do mundo dos wéinkupring, são outros tipos de seres, não humanos, nossos servidores.

Quando realizam o ritual do Kiki, as duas seções de cada metade se reúnem enquanto

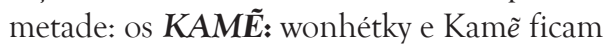
"no mesmo fogo", ocupam as três fogueiras que ficam a oeste da praça de dança (o lado onde fica a aldeia dos mortos, lado onde nasce a lua nova e o sol se põe) e a metade $K A \tilde{I} R U$ : kanhru e votor, ocupam as três fogueiras do lado leste, onde nasce o sol e a lua cheia. Entre as seções de cada metade distinguem-se variantes de um mesmo tipo de pintura; wonhétky, um risco longo da orelha até a boca, e Kamẽ dois riscos paralelos nas bochechas. No lado Kanhru, os Kanhru são marcados com dois ou três pontos na bochecha e às vezes na testa e votor são marcados com círculos abertos nos mesmos lugares. E cada tipo de pintura corresponde a uma seção, às pessoas são vinculadas por transmissão patrilinear, estando cada seção relacionada aos nomes próprios, que identificam o indivíduo e estabelecem o seu lugar social e cerimonial.

Apenas os péin podem circular nos dois espaços, separados por samambaia, na praça de dança, para levar a bebida e comida aos rezadores, agasalhá-los, aviventar o fogo das fogueiras. Ao irem ao cemitério observam rigorosamente uma hierarquia relacionada ao poder diante dos espíritos dos mortos. Os wonhétky entram primeiro no espaço do cemitério, seguidos pelos Kamẽ, depois entram os kanhru e, por último, entram os votor. Os da metade Kamẽ se dirigem às sepulturas dos Kanhru previamente identificadas com ramos da árvore "sete sangria" e os kanhru se dirigem às sepulturas dos Kamẽ, marcadas com ramos de pinheiro. Como os péin, atualmente, são enterrados no cemitério; suas sepulturas colocadas junto aos seus ascendentes são marcadas com ramos de samambaia.

Dessa forma, quem conhece a relação entre o nome e a seção correspondente a que 
ele pertença, sabe inclusive como relacionarse corretamente com seu portador: se como irmão (kaitkõ) [ortograficamente é kanhkã] ou como cunhado (iambré) e, ainda, e qual a atribuição cerimonial que lhe está destinada. Os membros de uma mesma metade referem-se uns aos outros como ikaitkõ, meu irmão (consangüíneo), e aos membros da metade oposta como ijambré, meu cunhado, pessoas do lado da minha mãe (afim). No Xapecó, enfatizavase a troca de irmãs entre pessoas da mesma geração; no Inhacorá e Rio da Várzea a relação entre gerações assimétricas kakrẽ (ou kakrõ), sogro, e iambré, genro é que era enfatizada. Se perguntamos aos Kaingang qual a relação entre o subgrupo ou seção Kamẽ e os Wonhétky e entre os Kaĩru e os Votor, costumam afirmar que seriam como "primo-irmão" (primos paralelos) que, no caso do parentesco Kaingang, são igualados a irmãos germanos. Isso equivale a dizer que, de fato, essa distinção não tem qualquer operacionalidade ao nível estrutural e pode ser reduzida à distinção fundamental entre as metades. Em trabalho anterior levanto a hipótese de que a instituição dessas subdivisões foi a maneira que os Kaingang encontraram para incorporar os filhos de pais não-Kaingang ao seu esquema cosmológico de metades opostas e complementares, marcando, no entanto, uma discreta hierarquia entre os descendentes diretos dos pais ancestrais KAMẼ e KAĨRU e os descendentes de homens incorporados à sociedade Kaingang por aliança ou como cativos de guerra (Veiga 1994: 70).

\section{Conclusão}

Os Jê Meridionais, Kaingang e Xokleng, talvez representem uma das raras possibilidades de se verificar a transformação política e social de grupos humanos das Américas nos últimos dois milênios através do estudo de estruturas arquitetônicas que envolvem movimentação de terra para construir habitações, espaços rituais e monumentos funerários.

O conhecimento etnográfico sobre os rituais relacionados aos mortos realizados pelos Kaingang e Xokleng até o final do século XX pode nos permitir obter as chaves para a análise de achados arqueológicos como os chamados danceiros e estruturas subterrâneas.

A etnografia revela que Kaingang e Xokleng conformam um complexo cultural, de forma semelhante, por exemplo, ao que a crônica seiscentista mostra acerca dos Tupinambás e Tupiniquins e seus rituais relacionados à guerra. A guerra entre si, como inimigos preferenciais, é um dos elementos que compõem o complexo cultural Jê Meridional (Veiga 2007). Em contrapartida, grupos Kaingang e Xokleng também se fundiam, em determinados contextos, por compartilharem concepções semelhantes sobre aliança, casamento e descendência. Além disso, compartilhavam crenças relativas à morte e aos mortos, que se estendem às mesmas práticas rituais, com o mesmo tipo de bebidas fermentadas (empregando até o mesmo nome para a bebida de hidromel, o kiki) e elementos de cultura material idênticos ou muito assemelhados (tanto nas práticas rituais, quanto no cotidiano, como no caso dos kur, com tecido de fibras vegetais). Por outro lado, a documentação etnográfica registra práticas distintas com respeito à iniciação dos jovens (perfuração e uso de batoque labial só ocorria entre os Xokleng) e aos enterramentos (até onde se sabe, cremação também foi uma prática exclusiva Xokleng), o que sugere desenvolvimentos também independentes, possivelmente advindos de contato e alianças culturais distintas.

A existência de grandes monumentos funerários, que se conhece como prática dos Kaingang até o começo do século XX, sugere a hipótese da constituição de uma sociedade hierárquica. Nesse aspecto, a leitura da documentação etnográfica que validaria ou não tal hipótese é mais difícil, devido ao uso comum de se projetar, nas sociedades indígenas, as práticas e valores da sociedade ocidental de onde provém o observador. $\mathrm{O}$ presente estudo mostra que uma leitura crítica e uma sistematização das fontes etnográficas, nesse aspecto, ainda precisa ser completado. Realizei com Wilmar D'Angelis um levantamento dessas fontes sobre o ritual para os mortos, do século XVII até o final do século XIX (D’Angelis e Veiga 1996: 92-108). 
VEIGA, J. Contributions of the Southern Jê Ethnography to Archaeology. VEIGA, J. Contribuição da etnografia dos Jê Meridionais à Arqueologia. R. Museu Arq. Etn, 27: 21-29, 2016.

Abstract: The Kaingang and Xokleng are the ethnic groups that constitute the Southern Jê branch. Despite their cultural transformations over time, deep and core conceptions of cultural identity are persistent - the case of the Kaingang who are extremely ingrained in some of their cultural referents. This text deals with some aspects of the cosmology and sociality of the Kaingang and emphasizes the relation of these two aspects with the construction of dwellings, ritual spaces and funerary monuments. The author seeks to emphasize that aspects of the use of space of the Kaingang and Xokleng can be identified by archaeological research.

Key words: Kaingáng; Xokléng; Cosmology; Sociality; Use of Space; Archaeology.

\section{Referências bibliográficas}

Barbosa, L.B.H. 1947. A pacificação dos índios Kaingáng Paulista. Hábitos, costumes e instituição desses índios. In: Barbosa, L.B.H. O problema Indígena do Brasil. Publicação da Comissão Rondon, 88, 34-72.

Borba, T.M. 1908. Actualidade Indigena. Impressora Paranaense, Curitiba.

D’Angelis, W.R.; Veiga, J. 1996. Fontes fundamentais para o estudo do ritual Kaingáng do Kikikoi. Anais do IV Encontro de Cientistas Sociais (I). Ijui, 92-108.

D’Angelis, W.R.; Veiga, J. 2014. A Mandioca era alimento antigo ou tradicional dos Kaingáng? (Manuscrito Inédito). 13 p.

Henry, J. ([1941] 1964). Jungle People: a Kaingáng tribe of highlands of Brazil. 2a ed.Vintage Books, New York, 1964. [1ª ed.: New York J.J. Augustin, 1941].

Maybury-Lewis, D. 1979. Dialectical Societies: the Gê and Bororo of Central Brazil. Harvard University Press, Cambridge/MA, P. 218-246.
Maniser, H.H. 1930. Les Kaingángs de São Paulo. XXIII International Congress of Americanists (New York 1928). New York, 760-791.

Maniser, H.H. 2006. Os Kaingáng de São Paulo. Ed. Curt Nimuendajú, Campinas.

Nimuendajú, C. 1993. Etnografia e Indigenismo. Sobre os Kaingáng, os Ofaié-Xavante e os indios do Pará. In: Gonçalves, M.A. (Org. e apresentação). Campinas, Editora da Unicamp.

Seeger, A.; Da Matta, R.; Viveiros de Castro, E. 1979. A construção da pessoa nas sociedades indígenas sul-americanas. Boletim do Museu Nacional (Antropologia), 32, 1-19.

Val Floriana, Frei M.B. 1920. Dicionários Kaingáng-Português e Português Kaingáng. Revista do Museu Paulista, São Paulo, vol. XII, 1-192.

Veiga, J. 1994. Organização Social e cosmovisão Kaingáng: Uma introdução ao parentesco, casamento e nominação em uma sociedade Jê Meridional. Dissertação de mestrado em Antropologia. UNICAMP, Campinas. 
Veiga, J. 2000. Cosmologia e práticas rituais Kaingáng. Tese de doutorado em Antropologia. IFCH, UNICAMP, Campinas.

Veiga, J. 2006. Aspectos fundamentais da cultura Kaingáng. Ed. Curt Nimuendajú, Campinas.
Veiga, J. 2007. A guerra como elemento constitutivo da sociabilidade dos Jê Meridionais. In: Rodrigues, A. e Cabral, A.S.A.C. (Orgs). Linguas e Culturas MacroJê. Brasília, Editora da UNB/Finatec, 109-125. 